\title{
Oral Hygiene (OHI-S) and DMFT Status among Type 1 Diabetic Adolescents Aged 12-19 Years: A Case-Control Study
}

\section{VASUDA BHAGAT ${ }^{*}$, MEHTAB SINGH BHAGAT $^{2}$}

INTRODUCTION: Diabetes in any form (type 1 or type 2 ) has the potential to affect the oral health of an individual.

AIM: To assess the oral hygiene status (simplified) and DMFT among adolescents aged 12-19 years with type 1 diabetes (cases) in Jammu District, Jammu and Kashmir (J\&K), India

MATERIALS AND METHOD: A total of 50 patients aged 12-19 years with type 1 diabetes mellitus, screened via medical history from August 2017 to August 2018 were enrolled in the study. The control group consisted of 51 healthy adolescents matched for age and gender selected randomly. The DMFT index was used to record the Decayed, Missing, Filled teeth, while the OHI-S Index was used to assess the Oral Hygiene Status. The examinations were done under artificial light and data was analyzed using SPSS version 19.0. The t-test, Odd's Ratio (OR) and multiple regression were used to analyze the data.

RESULTS: Of a total of 101 participants (50 cases and 51 controls) enrolled in the study, cases reported higher values of OHI-S and DMFT as compared to controls. The cases had an OHI-S score of $3.12 \pm 3.2$ indicating poor oral hygiene, the controls's score of $2.54 \pm 1.1$ revealed fair oral hygiene and no significant statistical differences were found $(\mathrm{OR}=2.1)$. A significant difference $(\mathrm{p}=0.03)$ was seen

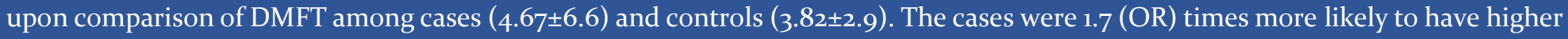
DMF values as compared to controls

CONCLUSION: Efforts must be reinforced among adolescents emphasizing the importance of oral health, through more frequent dental education camps in Jammu district, J\&K, India

KEYWORDS: Diabetes, OHI-S, DMFT, Adolescents.

\section{INTRODUCTION}

With two basic types [insulin dependent(type 1) and non-insulin dependent (type 2)], Diabetes mellitus is defined as a chronic metabolic disease affecting a

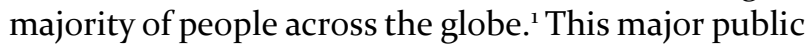
health problem affected an estimated 40 million people in India (2007) and by 2025, the estimates are that approximately, 70 million people shall be suffering from this disease in India alone. ${ }^{2}$

In spite of the above figures, this chronic disease is believed to have a high incidence in Europe and a low incidence in Asia. ${ }^{3}$ In addition, there is a growing concern over a rising incidence of children with diabetes type 1 across many countries ${ }^{4}$; also epidemiological studies by various authors on the same research hypothesis have yielded contradictory results. ${ }^{5-6}$

Overall, diabetic patients are associated with an intensive loss of fluids (due to polyuria), reduced/delayed response to infections, an impaired metabolism of the connective tissue and microvascular changes at many levels. These factors combined, are mostly responsible for diseases of an oral origin in diabetic patients, which include, but not limited to: xerostomia, salivary gland dysfunction, increased susceptibility to infections(bacterial, viral and fungal), periapical abscesses, tooth loss, taste altered/impairment, lichen planus, burning mouth syndrome (BMS), orthodontic tooth movements, dental caries and periodontal disease. ${ }^{7,8}$

Keeping in mind the above statements and with little or no data regarding the status of Oral hygiene status (simplified) and DMFT among adolescents aged 12-19 years with type 1 diabetes in Jammu district, J\&K, India the present study aimed to do the same.

\section{MATERIALS AND METHOD}

The present study, after obtaining an ethical clearance, consisted of a convenience sample of a total of 50 patients aged 12-19 years with type 1 diabetes mellitus, screened via medical history while attending a five private clinics/dental camps in Jammu district, J\&K, India from August 2017 to August 2018. The control group consisted of 51 healthy adolescents matched for age and gender, randomly selected from the same dental clinics.

On the day of clinical examination, both the parents and individuals with diabetes were given the patient information sheet and were informed about the aims 
and nature of the, study before signing the consent form. They were assured of the confidentiality of their data.

Dental examination was performed by five trained and calibrated examiners in a dental chair using a dental mirror, dental explorer and periodontal probe under light from the dental chair. All the data was recorded on a validated proforma for each participant. DMFT index was used to record the Decayed, Missing, Filled teeth, while the OHI-S Index was used to assess the Oral Hygiene Status. ${ }^{9}$

The collected data were analyzed using SPSS version 19.0 software (SPSS Inc, Chicago, IL, USA). Descriptive statistics were analyzed, and statistical inference was calculated using t-test, Odd's Ratio(OR) and multiple logistic regression.

\section{RESULTS}

Figure 1 depicts the study population. It was observed that a majority of the study subjects comprised of males [26 (Cases) \& 28 (Controls)]. The total participants enrolled in the study were 101 (50 cases and 51 controls).

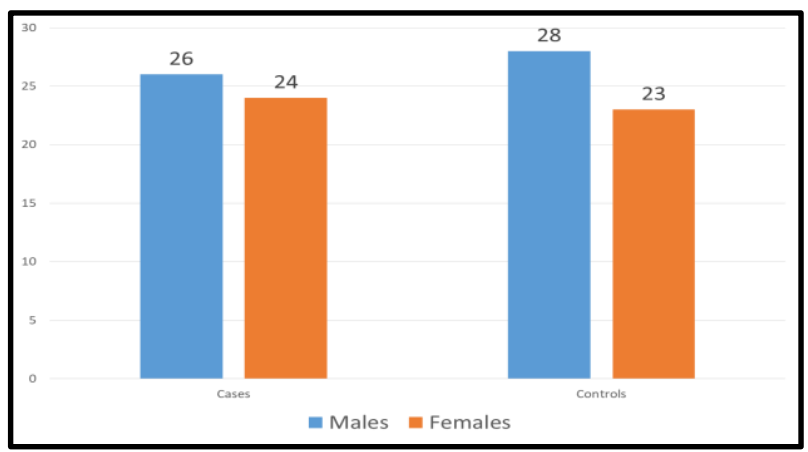

Figure 1. Distribution of the Study Subjects

The mean OHI-S and DMFT scores are shown in table 1 and the cases reported higher values as compared to controls. While the cases had an OHI-S score of $3.12 \pm 3.2$ indicating poor oral hygiene, the controls' score of $2.54 \pm 1.1$ revealed fair oral hygiene and no significant statistical differences were found $(\mathrm{OR}=2.1)$. A significant difference $(\mathrm{p}=\mathrm{0.03})$ was seen upon comparison of DMFT among cases $(4.67 \pm 6.6)$ and controls (3.82 \pm 2.9$)$. The cases were 1.7 (OR) times more likely to have higher DMF values as compared to controls.

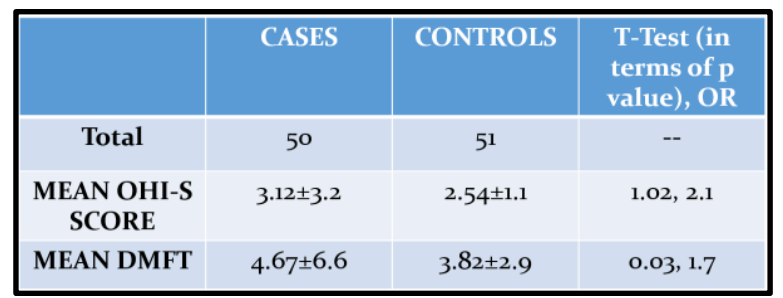

Table 1. Mean OHI-S and DMFT Scores of the Study Population

Multiple logistic regression to compare OHI-S and DMFT values among cases and controls revealed significant differences in the DMFT values, further strengthening the fact that type 1 diabetes has a significant role in causes an increased DMFT status as compared to controls (Table 2).

\begin{tabular}{|c|c|c|}
\hline $\begin{array}{c}\text { Independent } \\
\text { Variables }\end{array}$ & $\begin{array}{c}\text { OHI-S Parameter } \\
\text { Estimate (SE), p }\end{array}$ & $\begin{array}{c}\text { DMFT parameter } \\
\text { (SE), p }\end{array}$ \\
\hline Cases & $0.5(0.04)$ & $0.48(2.32)$ \\
Controls & .15 & .01 \\
\hline
\end{tabular}

Table 2. Multiple Logistic Regression Between OHI-S and DMFT among Cases and Controls

\section{DISCUSSION}

The present study, with the aim to assess the oral hygiene status (simplified) and DMFT among adolescents aged 12-19 years with type 1 diabetes (cases) in Jammu district, J\&K, India highlighted poor oral hygiene and higher DMFT(with a statistically significant difference) among cases as compared to their controls.

It was observed in the present study that no significant differences were seen between OHI-S status of the cases and controls and is in agreement with Siudikiene J et al. ${ }^{10}$ On the contrary, Pinson et al. ${ }^{11}$ and Busato et al. ${ }^{12}$ did not find a positive correlation between glycemic control and oral hygiene in their respective studies. It was also observed that a poor OHI-S Score was seen among cases in comparison to a "fair" score seen in the controls. This indicates that while the need for promotion of oral health services needs to be directed among all the adolescents of Jammu district, J\&K, India, special care needs to be diverted to diabetics. 
Significant and higher differences were observed between the DMFT scores among cases and controls and is in agreement with Norallah AW et al. ${ }^{4}$ and Bissong et al., ${ }^{13}$ Maria Moin et al. ${ }^{14}$ Malicka et al. ${ }^{15}$, while, irreconcilable results were shown by Qureshi et al. ${ }^{16}$ Researchers have speculated that the reason behind such a high prevalence is that salivary glucose level among the diabetic patients is very high, which in turn favours the propagation of microorganisms and help facilitate their accumulation on tooth surface, leading to formation of plaque and calculus, which lead to dental caries. Such results highlight the importance of providing dental care to such a population as it is well known that adolescents on average clean their teeth less frequently than after adolescence, which might lead to even poor hygiene and an increased DMFT status. ${ }^{17}$

This study, although exploratory in nature, has provided gainful insights regarding the oral hygiene status and DMFT status of adolescents aged 12-15 years of Jammu district, J\&K, India and directs the need for further studies in this context. However, this study is prone to certain limitations: the first being the selection of convenience sampling, which included walk-in patients in dental clinics only; second being that due to exploratory nature of the study, diabetic status of the study subjects (controlled or uncontrolled) was not recorded and could have possibly affected the prevalence of OHI-S and DMFT among the study subjects. However, it is safe to say that the results can be extrapolated to adolescent's suffering from type 1 diabetes due to a strong statistical correlation seen in context of DMFT status.

\section{CONCLUSION}

It is highly recommended that efforts must be reinforced among adolescents emphasizing the importance of oral health, necessitating the need for more dental education camps in Jammu district, J\&K, India.

\section{REFERENCES}

1. Karam JH. Pancreatic hormones and diabetes mellitus. In: Greenspan FS, Strewler GJ, editors. Basic and clinical endocrinology. $5^{\text {th }}$ ed. New Jersey: Appleton and Lange, 1997:595-663.

2. Goyal D, Kaur H, Jawanda MK, Verma S, Parhar S. Salivary $\mathrm{pH}$ and dental caries in diabetes mellitus. Int J Oral Maxillofac Surg. 2012;3:13-6.

3. Karvonen M, Tuomilehto J, Libman I, LaPorte R. A review of the recent epidemiological data on the worldwide incidence of type 1 (insulin-dependent) diabetes mellitus. World Health Organization DIAMOND Project Group. Diabetologia 1993;36:88392.

4. Norallah AW, Kassis M. Oral Health Status Of Children With Type 1 Diabetes Mellitus: A Comparative Study. Int J Dent Health Sci 2018; 5(2):274-80.

5. Lin B P, Taylor G W, Allen D J, Ship J A. Dental caries in older adults with diabetes mellitus. Spec Care Dentist; 1999 19: 8-14.

6. Siudikiene J, Machiulskiene V, Nyvad B, Tenovuo J, Nedzeiskiene I. Dental caries and salivary status in children with type 1 diabetes mellitus related to the metabolic control of the disease. Eur J Oral Sci 2006; 114: 8-14.

7. Darnell JA, Saunders MJ. Oral manifestations of the diabetic patient. Tex Dent J. 1990;107:23-7.

8. Diabetes Action Now. Vol. 58. Geneva, Switzerland: Int Dent J; 2008. WHO/International diabetes federation; pp. 265-8.

9. WHO. Oral health surveys-basic methods. 3rd ed. Geneva: World Health Organization 1987.

10. Siudikiene J, Maciulskiene V, Dobrovolskiene R, Nedzelskiene I. Oral hygiene in children with type I diabetes mellitus. Stomatologija. 2005;7(1):24-7.

11. Pinson M, Hoffman WH, Garnick JJ, Litaker MS. Periodontal disease and type diabetes mellitus in children and adolescents. J Clin Periodontol. 1995;22(2):118-23.

12. Busato IMS, Bittencourt MS, Machado MÂN, Grégio AMT, Azevedo-Alanis LR. Association between metabolic control and oral health in adolescents with type 1 diabetes mellitus. Oral Surg Oral Med Oral Pathol Oral Radiol Endod. 2010;109(3): e51-e5

13. Bissong M, Azodo C, Agbor M, Nkuo-Akenji T, Fon P. Oral health status of diabetes mellitus patients in Southwest Cameroon. Odontostomatol Trop. 2015;38(150):49-57.

14. Moin M, Malik A. Frequency of dental caries and level of risk among type II diabetics. Dentistry. 2015;5:1-5.

15. Malicka B, Kaczmarek U, Ziętek M. Dental caries in adult patients with type 1 and 2 diabetes mellitus. J Stoma. 2011;64:9-24.

16. Qureshi A, Qureshi A, Qureshi H, Khan AA. Blood glucose level, Salivary $\mathrm{pH}$ and oral bacterial count in type 1 diabetic children. Infect Dis J. 2007;16:45-8.

17. Kneckt MC, Syrjälä AMHS, Knuuttila MLE. Attributions to dental and diabetes health outcomes. J Clin Periodontol; 27:205-11. 
Cite this article as:

Bhagat V, Bhagat MS. Oral Hygiene (OHI-S) and DMFT Status among Type 1 Diabetic

Adolescents Aged 12-19 Years: A Case-Control Study. Int Healthc Res J. 2018;2(10):260-263.

Source of support: Nil, Conflict of interest: None declared

doi: 10.26440/ihrj.v2i10.194

\section{AUTHOR AFFILIATIONS:}

1. PG Student, Department of Oral Medicine and Radiology, DJ College of Dental Sciences and Research, Modinagar

2. MBBS, Sher-i-Kashmir Institute of Medical Sciences (SKIMS), Jammu and Kashmir

\section{${ }^{*}$ Corresponding Author:}

Dr. Vasuda Bhagat

PG Student, Department of Oral Medicine and Radiology

DJ College of Dental Sciences and Research

Modinagar
For article enquiry/author contact details, e-mail at: editor.ihrj@gmail.com, editor@ihrjournal.com 